\title{
Pesquisa Intervenção e Análise Institucional: alguns apontamentos no âmbito da pesquisa qualitativa.
}

\author{
Edna Ferreira Coelho Galvão ${ }^{1}$ \\ Juarez Bezerra Galvão ${ }^{2}$
}

\begin{abstract}
In the last three decades, a great process of searching for new ways of looking at and understanding reality has been installed in the areas of human and social sciences. A universe of possibilities was drawn in the field of qualitative research, in this article, some reflections are proposed around the institutional analysis and the research intervention in articulation with the genealogy of Foucault. It is hoped to contribute to the debate around the research methods, as well as to make possible other research paths within the institutions, considering the institution and the institute as a space full of vicissitudes to be apprehended and understood from the relations of know-power.
\end{abstract}

Resumo. Nas últimas três décadas instalou-se nas áreas das ciências humanas e sociais um grande processo de busca de novas forma de olhar e compreender a realidade. Um universo de possibilidades desenhou-se no campo da pesquisa qualitativa, neste artigo, propõem-se algumas reflexões em torno da análise institucional e da pesquisa intervenção em articulação com a genealogia de Foucault. Espera-se contribuir com o debate em torno dos métodos de pesquisa, assim como, possibilitar outros caminhos de investigação no âmbito das instituições, considerando o instituído e o instituinte como espaço cheio de vicissitudes a serem apreendidas e compreendidas a partir das relações de saber-poder.

\section{Introdução}

O contexto sócio-hitórico desenhado a partir dos eventos ocorridos nas décadas de 80 e 90 do século XX, possibilitou ao Brasil a ampliação e divulgação de um universo muito criativo de abordagens e caminhos metodológicos no âmbito das pesquisas nas ciências sociais e humanas. Muitos pesquisadores se lançaram às pesquisas seguindo enfoques principalmente do tipo femenológico-hermenêutico ou crítico dialético, guiados pela necessidade de imprimir uma crítica ao paradigma positivista e/ou impelidos a encontrar outras possibilidades de apreensão e compreensão dos fenômenos que preocupavam a sociedade da época. As diferentes áreas das ciências sociais e humanas começam a rever seus paradigmas epistemológicos, e mediante uma autocrítica profunda, empreenderam um processo de mudança na forma de compreender a realidade e produzir conhecimentos.

\footnotetext{
${ }^{1}$ Doutora em Educação pela UFF. Professora da PPG da UEPA - Mestrado Profissional Ensino em Saúde. Professora Colaboradora do PPG da UFOPA - Mestrado acadêmico em Ciências da Sociedade. Líder do GEPESPA. Email: efcgalvao@gmail.com

${ }^{2}$ Doutor em Educação pela PUC-SP. Professor Associado da UFOPA. Professor do PPG da UFOPA - Mestrado acadêmico em Ciências da Sociedade. Email: juarezgalvao@ufpa.br
} 
Neste contexto, principalmente via programas de pós-graduação estrito sensu, começam a ser produzidas e divulgadas no Brasil diferentes formas de investigar, compreender e interpretar a realidade. A Análise Institucional, criada na França na década de 60 deste mesmo século, foi uma desta possibilidades, assim como a pesquisa intervenção. Este artigo se propõe trazer algumas reflexões sobre a pesquisa qualitativa no âmbito da Análise Institucional e da Pesquisa Intervenção em articulação com a genealogia de Foulcault.

\section{A pesquisa qualitativa e a análise institucional}

Grande parte das pesquisas científicas esteve e está atrelada à busca da verdade objetiva, das explicações lógicas e medidas quantitativas de caráter universal. Neste contexto, o pesquisador é movido pela curiosidade e sua ação se restringe a descobrir como o fenômeno se manifesta. Para tanto, o sujeito-pesquisador deve manter uma certa distância do objeto a ser investigado, a fim de não interferir nos resultados com seus valores e concepções, constituindo, assim, a neutralidade científica. A crítica a este paradigma científico surgiu de inúmeros debates advindos, principalmente, das ciências sociais e políticas, além do que as discussões no âmbito da epistemologia produziram diferentes argumentos, criando novos entendimentos acerca da pesquisa. Superou-se a concepção de pesquisa apenas como possibilidade de descobrir algo que já existe, muito próprio das ciências naturais; pesquisar também é intervir e criar conhecimento novo. Para Assmann,

\footnotetext{
toda análise já contém uma proposta de intervenção na realidade. Hoje, mais do que nunca, é ilusória qualquer pretensão de neutralidade do processo de pensamento. Por isso mesmo, pensar é sempre posicionar-se. Isso considerado fica evidente que o enfoque metodológico jamais se reduz a meros bisturis teóricos; categorias e conceitos, e sua articulação recíproca. No bojo do marco teórico sempre existem pressupostos tácitos acerca das manutenções ou transformações possíveis - desejáveis ou não - do mundo. É certo que não se lê o real sem articular sua interpretação mediante um conjunto de categorias e conceitos. São lentes, lupas e bisturis, sem os quais permaneceremos cegos. Mas o que se vê, pelos olhos das ciências, sempre contém, como na visão ocular - a outra visão: a criada pelo cérebro, no caso da vista; a criada pela esperança ou a resignação no caso do saber (In: AZEVEDO, 1997, p. 03).
}

A crítica à neutralidade científica, aos métodos experimentais e objetivos de análise dos problemas sociais, defendida pelo paradigma positivista nas ciências, levou ao desenvolvimento de teorias/abordagens que defendem a aproximação/imbricação entre pesquisador e participante de estudo, mostrando as múltiplas interferências entre ambos. Isto só foi possível à medida que as condições materiais de subsistência foram (re)construídas historicamente; permitindo um outro olhar para as relações sociais a partir de novos direcionamentos para a investigação dos fenômenos 
sociais. Esta realidade provocou significativas rupturas na forma como se produzia o conhecimento científico.

Neste contexto, as contribuições significativas da fenomenologia e da Psicologia Social afirmaram ser inviável à compreensão do fenômeno quando o pesquisador se coloca distante/externo ao campo de investigação. O que se convencionou chamar de pesquisa qualitativa se constrói neste contexto de busca de um caminho metodológico capaz de permitir uma compreensão mais profunda dos fenômenos sociais, tendo em vista a necessidade de encontrar vias de explicação e soluções para os inúmeros problemas da vida em sociedade.

Partindo deste paradigma, é possível perceber o quanto o objeto de investigação das ciências sociais é eminentemente qualitativo, tendo em vista só ser possível apreendê-lo por meio de uma aproximação efetiva entre pesquisador e participante/campo de estudo. A realidade social apresenta ao pesquisador fenômenos complexos e prenhe de significados, impondo a qualquer teoria ou pensamento construído sobre ele, a necessidade de trazer/apresentar seus limites; uma vez que ao pensar e elaborar uma explicação o pesquisador faz escolhas, fatalmente ele estabelece um processo de divisão, separação e distinção, próprios do processo de nomeação e compreensão dos objetos e da relação homem-mundo. A pesquisa qualitativa compreende e acolhe estes limites. Diante disso, é impossível falar em neutralidade. Na relação pesquisador e realidade a ser investigada, outro aspecto mostra-se importante, a noção de implicação. Algumas pesquisas qualitativas assumem a implicação como processo importante na investigação científica, pois como destaca Paulon (2005, p. 19), “o observador inserido em seu campo de observação transforma, por definição, seu objeto de estudo. A necessidade de incluir-se, portanto, no processo investigativo, a subjetividade de quem pesquisa como categoria analítica já se apresenta aí, anunciando as bases do conceito institucionalista de implicação".

A pesquisa, nesta perspectiva, passou a ser concebida como processo de construção de conhecimento a partir de uma relação constante entre pesquisador e realidade pesquisada. $\mathrm{O}$ que significa dizer que há um processo mútuo de interferência que precisa ser considerado e analisado. Este contexto é atravessado pelos modos de subjetivação ${ }^{3}$, pois a produção do conhecimento está

\footnotetext{
${ }^{3}$ Para Guatarri e Rolnik (2000, p. 31), o conceito de subjetividade não se confunde com o conceito de individualidade. Para ele "os indivíduos são o resultado de uma produção de massa. O indivíduo é serializado, registrado, modelado [...]. A subjetividade não é passível de totalização ou de centralização no indivíduo. Uma coisa é a individuação do corpo. Outra é a multiplicidade dos agenciamentos da subjetivação: a subjetividade é essencialmente fabricada e modelada no registro social". O autor traz importantes contribuições no sentido de nos ajudar a superar aquela visão intimista, a-histórica, abstrata, natural ligada ao conceito de individualidade, para ao contrário mostrar
} 
intimamente ligada à produção da fala, do discurso, da sensibilidade, do desejo, das imagens, dos símbolos, das práticas, e "essa produção é adjacente a uma multiplicidade de agenciamentos sociais, a uma multiplicidade de processos de produção maquínica, a uma mutação de universos de valor e históricos" (GUATTARRI, 2000, p. 32).

Essa forma de conceber e produzir a pesquisa considera o envolvimento de diferentes posições, olhares, concepções e interlocuções que, num processo histórico, vão construir consensos e conflitos, tecendo uma teia e a trama cotidiana. Assim, a pesquisa se corporaliza negociando momentos de falas e silêncios, promovendo o reconhecimento da realidade, constituindo-se a partir de relações de cumplicidade e engajamento (GALVÃO, 2004).

É possível dessa forma, pensar a pesquisa como processo de formação histórica das pessoas e grupos à medida que significa o domínio do conhecimento da realidade que os circunda. Pesquisar, então, subentende construir saber. Todo saber compreendido como prática, acontecimento, “como uma peça de um dispositivo político, [...] se articula com a estrutura econômica”. O saber na perspectiva foucaultiana, possibilita construir novas relações de poder, todo saber assegura o exercício de um poder. "Poder capaz de intervir materialmente e atingir a realidade concreta dos sujeitos - seu corpo - situado ao nível do corpo social, penetrando na vida cotidiana, se constituindo num micro-poder". (FOUCAULT, 1979, p. XII).

$\mathrm{Na}$ articulação entre saber-poder, a pesquisa não se apresenta apenas como construção de conhecimento, mas também como atitude política, o que significa engajar-se em movimentos de revisão, intervenção e reestruturação, processando uma mudança recíproca entre pesquisador e realidade. O pesquisador, querendo ou não, assume decisões que refletem sua posição/concepção de mundo e produz saber segundo determinados interesses. Os procedimentos que se utiliza, a relação que estabelece com os participantes da pesquisa, a linguagem e a forma como escreve, assim como o compromisso ou não com a socialização dos resultados demonstram sua atitude política (GALVÃO, 2004).

Transcrever o que se pensa, observa, ouve, instaura um processo de reflexão acerca das próprias vivências, dos princípios, dos valores e pontos de vista, possibilitando um novo olhar sobre si mesmo, sobre as relações que se estabelece com o outro e a forma como se age e se coloca diante do mundo. A escrita coloca-se como instrumento político fundamental de conexão entre que a construção dos sujeitos se dá dentro de uma cultura de massa, produzindo comportamentos, valores, normas, corpos submissos, disciplinados e hierarquizados socialmente. 
o pesquisador/pesquisa e os sujeitos/realidade, ora se apresenta como possibilidade de reflexão e transformação, ora como institucionalização e imobilização.

Neste tipo de pesquisa, o sujeito-pesquisador, estabelece uma relação de análise e autoanálise de suas implicações com o projeto que vem desenvolvendo. Portanto, não é possível assumir o princípio científico de afastamento, neutralidade; pelo contrário, é necessário assumir os ônus e os bônus de suas implicações. O projeto político do intelectual implicado inclui a intenção de transformar a si mesmo e o seu lugar social, a partir de estratégias de coletivização das experiências e análises (LOURAU, 1993, p. 85).

Neste sentido, a investigação representa um momento do trabalho cheio de significados construídos historicamente; parte daí a necessidade de refletir sobre o envolvimento do pesquisador com a realidade pesquisada, assim como as interferências da pesquisa em sua vida. Dessa forma, é importante afastar-se da noção de sujeito e objeto separados para assumir a noção de transversalidade das relações ${ }^{4}$.

A partir destes princípios, na década de 60 do século passado, surgem inúmeras abordagens dos fenômenos sociais, com base na filosofia marxista, isto se deu em meio a um grande movimento contra-cultural e de crítica à alienação. Neste período na França surge a Análise Institucional (AI) (RODRIGUES, 2002). Este tipo de pesquisa permite explicar comportamentos e opiniões de diferentes pessoas pertencentes a grupos ou coletivos de qualquer natureza, ajudando-os a conhecer a si mesmos, suas necessidades, os entraves à realização de seus objetivos ou de seu crescimento pessoal ou coletivo. A AI prevê a intervenção nestes grupos ou coletivos, registrando o que for importante (opiniões, normas, atos administrativos etc.), apresentando as condições em que se encontram, as dificuldades, as deficiências e os desiquilíbrios, oferecendo informações que podem favorecer uma tomada de decisão (LIMA; RIANE, 2004).

O desenvolvimento da AI se deu a partir de três caminhos importantes: o primeiro brota dos estudos de Félix Guattari que desenvolveu importantes conceitos para a AI, como por exemplo, o de analisador e de transversalidade, com base nas práticas da saúde mental, via psicoterapia

\footnotetext{
${ }^{4} \mathrm{O}$ conceito de implicação é apresentado pela Análise Institucional da seguinte forma: "a análise das implicações não consiste somente em analisar os outros, mas em analisar a si mesmo a todo instante, inclusive no momento da própria intervenção. As coisas que dizemos trazem as marcas das posições políticas, materiais e libidinais que assumimos, dizem respeito ao lugar que ocupamos nas relações sociais". (LOURAU, 1993, p. 36) O conceito de transversalidade traz a compreensão das forças sociais que nos constituem. As referências políticas, econômicas, culturais, ideológicas, sexual, libidinal, etc que entrecruzam nossas vidas e produzem diferentes formas de subjetivação (GUATTARI,1986).
} 
institucional, realizada em hospital psiquiátrico a partir da década de 40 do mesmo século; o segundo, vinculado à Pedagogia Libertária, que promove um profícuo questionamento da educação vigente pós 1950, e que ficou conhecido como Pedagogia Institucional, tendo René Lourau e Georges Lapassade como difusores. E o último, a Psicossociologia ligada a técnicas de grupo criadas nos EUA por Moreno, Lewin e Rogers (ROSSI; PASSOS, 2014).

Kurt Lewin rompe com os princípios positivistas de neutralidade do pesquisador, defendendo a posição de pesquisador envolvido com o campo de investigação e, portanto, constituído de "forças, vetores e valências" produzidas nas relações neste espaço. Ele propôs a pesquisa-ação como possibilidade de modificação do objeto de estudo. Contudo, o paradigma da pesquisa-ação lewiniana atendeu mais aos interesse governamentais, seja na formação de trabalhadores, estratégias de guerra ou em processos de (re)socialização de grupos delinquentes e/ou marginais. E, neste particular, atendeu muito mais a uma perspectiva de funcionamento e ordem social, do que à revisão de processos de subjetivação (RODRIGUES 1994; PASSOS e BENEVIDES, 2000; AGUIAR e ROCHA, 2003).

Das questões acima mencionadas, vale a pena destacar as contribuições de René Lourau e Georges Lapassade no campo da pedagogia; utilizando-se da dialética instituído/instituinte, definiu as instituições como forma (instituído) e a sociedade (instituinte) como processo. As instituições "produzem e reproduzem as relações sociais e se instrumentalizam em estabelecimentos e/ou dispositivos" (RODRIGUES; SOUZA, 1987). Com isso, eles produziram um distanciamento entre o conceito de instituição e o de organização e estabelecimento, permitindo ampliar a análise para processos/práticas instituintes engendrados pelas instituições e que atravessam os diferentes espaços e situações. Criando a Análise Institucional (AI) (ROSSI; PASSOS, 2014).

$\mathrm{Na} \mathrm{AI}$ o pesquisador se torna um ator social, ao aproximar-se do campo de investigação e se propor a conhecê-lo por dentro, ele assume um papel social que mesmo que não queira, interfere no cotidiano das relações. Intervir em pesquisa, significa construir o objeto de estudo por dentro, consciente de que este processo também o constrói a si mesmo. Portanto, ele mesmo e seu envolvimento com a realidade, também, devem ser analisados. É a análise de suas implicações (LOURAU, 1975). Entretanto, a análise das implicações não é tarefa fácil, pois faz-se necessário desnudar as ações revelando suas fraquezas, erros e limitações, pois, 
mundo. Ou, por exemplo, em nosso local de trabalho. Um coletivo de trabalho urge que 'ocultemos' de nós mesmos, digamos, $80 \%$ de seu funcionamento real (ou 'relacional' ). Inclusive, necessita desse 'ocultamento' para funcionar. É a verdade, a realidade. Não é mau, apenas, contraditório (LOURAU, 1993, p. 14 -15).

Grande parte dos problemas sociais que a sociedade enfrenta, como por exemplo, a violência, o desordenamento urbano, o desmatamento e extinção de várias espécies animais e vegetais, a miséria, a desnutrição, a falta de acesso à saúde pública etc. são consequências de uma forma de ver o mundo, de produzir a subsistência humana, de construir as relações sociais e também de financiar e desenvolver pesquisas. As intenções que geram as produções científicas muitas vezes estão mais a serviço de um poder econômico-político, que segrega e classifica os sujeitos em classes sociais, do que atentos às necessidades imediatas de grande parte da população. Suas consequências, intervenções e implicações são em grande parte desconsideradas em prol de um novo conhecimento, de uma nova descoberta. A AI busca "não fazer um isolamento entre o ato de pesquisar e o momento em que a pesquisa acontece na construção do conhecimento. Quando falamos em implicação com uma pesquisa, nos referimos ao conjunto de condições da pesquisa" (LOURAU, 1993, p. 16).

Neste sentido, o pesquisador deve assumir sua inseparabilidade do contexto da pesquisa. Reconhecendo que, em vários momentos, provavelmente não conseguirá ouvir/ver o que a realidade lhe diz/mostra, da mesma forma que em outros momentos deverá perceber a impossibilidade ou limite diante da investigação. É inevitável priorizar determinadas vozes, ações e relações no desenrolar do estudo, assim como agir como cúmplice, seja diante do silêncio ou do som mais agitado das reivindicações. Por outro lado, este tipo de pesquisa também compromete o pesquisador com a restituição, pois traz à tona falas, ações, comportamentos, olhares que, em geral, são deixadas de lado, "à sombra". Coisas que são observadas/ouvidas no cotidiano das relações, longe de ouvidos “inimigos”, enfim, “tais coisas são aquelas 'fala' institucional que não pode ser 'ouvida' de forma pública” (LOURAU, 1993, p. 52).

Dar destaque às coisas que comumente ficam às sombras, relegadas ao silêncio, é uma importante forma de rever o vivido e contar uma outra história. A AI permite produzir diferentes expressões e silenciamentos, desestrutura para conhecer o que está estruturado e, muitas vezes, reproduz o que já estava posto. Neste contexto, é necessário admitir que a pesquisa é um instrumento de poder e em decorrência disso, prioriza determinadas vozes e sujeitos. Deixa ao esquecimento 
aqueles(as) que não interessam, marginalizando, às vezes, grande parte dos acontecimentos. O pesquisador, no teor da pesquisa intervenção, precisa tomar algumas decisões, escolher as atividades a serem desenvolvidas, as ações que serão implementadas e registradas, as vozes, os olhares e relações que serão privilegiadas, assim como os pressupostos teórico-metodológicos que nortearão suas análises.

\section{A pesquisa-intervenção e a genealogia de Foucault}

A pesquisa intervenção surge na França na década de 1960, a partir de uma crítica à pesquisa-ação, uma vez que esta não consegue superar a visão dicotômica, de origem positivista, entre teoria e prática e objeto de investigação, ficando presa à mesma lógica cientificista que tanto repudiou. Por outro lado, o primeiro mundo estava envolvido por movimentos de contestação e críticas aos regimes totalitários e à centralização partidária; da mesma forma que havia um maior acesso à formação acadêmica e um processo em curso de ampliação da democratização dos países, o que influenciou, em grande medida, os questionamentos da perspectiva conscientizadora e sensibilizadora da pesquisa-ação. Neste contexto, é gestada uma abordagem que se preocupa em compreender os jogos de interesse e de poder presentes no espaço de pesquisa, a Pesquisa Intervenção (PAULON, 2005).

A Pesquisa Intervenção pressupõe saber ouvir e conviver com o diferente, desenvolver atividades que possam constituir-se em acontecimentos analisadores ${ }^{5}$, enfrentar os próprios limites e medos; registrar cada passo, cada reação e cada fala são processos importantes na coleta de dados. Outros desafios desse tipo de investigação constituem a capacidade de considerar as diferentes visões que ambientam o espaço da pesquisa, assim como, as posições divergentes, as aproximações e afastamentos, a necessidade de horizontalizar a relação pesquisador/participante do estudo, colocar em cheque a organização e as relações instituídas privilegiadas no espaço de investigação, somos também as implicações do pesquisador, suas escolhas. Este direcionamento possibilitará profundas experiências e a identificação de processos de singularização ${ }^{6}$ que em outros tipos de

\footnotetext{
${ }^{5}$ Acontecimentos produzidos individualmente, ou em grupo, que trazem à tona as contradições na lógica da organização social, com objetivo de fazer surgir comportamentos, atitudes, falas etc., que de outra forma não se manifestariam, permitindo analisar os processos de institucionalização presentes nas relações que os sujeitos estabelecem, ou seja, suas determinações (COIMBRA, 1995a).

${ }^{6}$ Guatarri e Rolnik apresentam o conceito de singularidade em contraposição ao conceito de individualidade. A individualidade seria produzida capitalisticamente dentro da cultura de massa, o que significa produzir indivíduos normalizados, hierarquizados, submissos. O processo de singularização se oporia a essa máquina de produção, seria "uma maneira de recusar todos esses modos de codificação preestabelecidos, todos esses modos de manipulação e de
} 
pesquisa não são percebidos. Esses processos são capazes de mostrar a potência da singularidade existente nos ambientes de pesquisa (GALVÃO, 2004).

Coimbra chama a atenção para a importância da análise das implicações na pesquisa intervenção:

\begin{abstract}
A proposta de analisar nossas implicações é uma forma de pensar, cotidianamente, como vêm se dando nossas diferentes intervenções. Dentro de uma visão positivista que afirma a objetividade e a neutralidade do pesquisador, as propostas da Análise Institucional tornam-se, efetivamente, uma subversão. Colocar em análise o lugar que ocupamos, nossas práticas de saber-poder enquanto produtoras de verdades - consideradas absolutas, universais e eternas - seus efeitos, o que elas põem em funcionamento, com o que se agenciam é romper com a lógica racionalista presente no pensamento ocidental e, em especial, na academia (COIMBRA e NASCIMENTO, [2003-], p. 03 ).
\end{abstract}

Considerando esta realidade, o pesquisador analista deve permitir que sua pesquisa seja reestruturada de acordo com os acontecimentos do cotidiano, pois eles são capazes de alterar a compreensão/percepção do que vem a ser: o sujeito/indivíduo; a relação; o lugar e o espaço; o papel social; a instituição e o instituinte. A opção pela pesquisa-intervenção se dá na medida em que o pesquisador percebe que ela oferece a oportunidade de atuar diretamente no campo da pesquisa, estabelecendo/criando práticas/dispositivos que se constituem em acontecimentos diferenciadores, com grande potencial de análise. Sendo este um ponto fundamental considerando a situação de subserviência/utilidade que, historicamente, envolve as relações institucionais.

O sujeito adaptado/passivo sempre foi uma prioridade para as instituições. Os diferentes sistemas instituíram lugares e comportamentos desejáveis para todos que participam de uma dada instituição. Todos devem submeter-se às normas, à organização e à hierarquia, como condição básica de existência/sobrevivência. Este lugar é incorporado naturalmente pelos diferentes sujeitos sem considerar o contexto sócio histórico que o produziu.

Desta forma, a disciplina/autodisciplina, o modelo e o controle tem sido presente na formação/constituição dos sujeitos com processos cada vez mais sutis, convencendo e naturalizando comportamentos segundo regras e interesses alheios aos seus sujeitos. A organização dos espaços/tempos institucionais estabelece lugares e horários para cada atividade/gesto/comportamento,

telecomando, recusá-los para construir, de certa forma, modos de sensibilidade, modos de relação com o outro, modos de produção, modos de criatividade que produzam uma subjetividade singular. Uma singularização existencial que coincida com um desejo, com um gosto de viver, com uma vontade de construir o mundo no qual nos encontramos, com a instauração de dispositivos para mudar os tipos de sociedade, os tipos de valores que não são os nossos" (2000, p.17). 
assim como, separa, seleciona o que é permitido e o que é proibido e para quem. Enfim, o espaço e tempo institucional estão milimétricamente organizados atendendo à função a que se destina. Apesar de todo este controle, é notória a presença de comportamentos que questionam a ordem vigente, tais como processos de violência, indisciplina, conflitos, inadequações, revolta, enfrentamento, apatia, fracasso. As instituições podem se defrontar, no seu cotidiano, com atitudes e situações inesperadas e, muitas vezes, indesejadas. Neste contexto, a pesquisa intervenção surge como alternativa para propor práticas que fujam às regras e levantem questões, muitas vezes silenciadas ou desconsideradas; é uma oportunidade de analisar os processos de produção de significados e comportamentos nesses espaços (GALVÃO, 2004).

A tradição corporal das instituições, muitas vezes engessam conceitos/percepções, dificultado que os sujeitos se permitam vivenciar situações inusitadas ou estabelecer relações mais prazerosas com o ambiente que habitam. Por outro lado, esta mesma tradição também aponta para a capacidade dos sujeitos produzirem mecanismos próprios de interação e proteção de seus espaços. A pesquisa-intervenção, segundo os pressupostos da análise institucional, possibilita analisar os significados que os sujeitos atribuem aos diferentes espaços que circulam, assim como as práticas permitidas ou concebidas nestes espaços. Esta análise permiti entender as diferentes concepções acerca da função da instituição; os mitos, as superstições e pré-conceitos; os modos próprios de falar ou de silenciar; os medos e receios; assim como, o envolvimento do pesquisador com a realidade investigada e os reflexos que sofre no processo de interação com a mesma, enfim, os modos de corporalização produzidos no contexto da pesquisa (GALVÃO, 2004).

As percepções apresentadas pelos participantes da pesquisa, muitas vezes, podem se contrapor à visão do pesquisador. Para não adotar uma postura elitista, um caminho é assumir a perspectiva genealógica de Foucault (1979). A genealogia representa a possibilidade de problematizar as práticas sociais de dentro. Para Lemos e Cardoso Jr (2009, p. 353), Foucault se propôs a problematizar a história, produzindo questionamentos, estabelecendo estranhamentos e espanto, num "exercício constante de demolição das evidências". Em sua genealogia, ele procurou escapar das relações causais para problematizar as práticas discursivas, de saber e poder e de subjetivação, responsáveis por produzir uma determinada forma de ser, pensar, agir e sentir de um tempo e lugar específico (CARDOSO JR., 2001).

Marton (2001, p. 47) destaca que a genealogia nietzschiana deve ser compreendida "como 
análise da proveniência e história das emergências", para ele a proveniência não significa continuidade ou semelhança, mas a possibilidade de uma ideia/sentimento, do diferente, do desvio ou acidente de percurso, significa apontar heterogeneidades daquilo que se imaginava homogêneo. $\mathrm{E}$ a emergência não pode ser confundida com a busca de antecedentes, de um costume, da origem, mas de encontrar "o ponto de seu surgimento; não cabe compreendê-los a partir dos fins a que se destinariam, mas detectar um certo estado de forças em que aparecem".

Foucault se apropria da Genealogia de Nietzsche, para propor uma história que priorize o descontínuo e faça ressurgir o acontecimento no que ele tem de único e agudo. Essa história se constitui em devir e mutação, é produzida ao acaso dos acontecimentos, se faz pela metamorfose. Desse modo, o genealogista tem a tarefa de promover a dispersão dos acontecimentos, estabelecer um corte entre a palavra e a coisa, problematizando as relações de saber-poder presentes na produção de saberes e subjetividades (FOUCAULT, 1979).

A pesquisa intervenção na perspectiva genealógica de Foucault propõe-se considerar o momento em que todos, envolvidos na pesquisa, se encontram; de onde olham e o que olham; isto ajuda a perceber o ângulo que determina o olhar e, consequentemente, o que se aprecia ou não, o que se permiti ou não emergir durante a pesquisa. A história genealógica possibilita olhar para a realidade sem a preocupação de fazer julgamentos, estabelecer verdades, formar grandes teorias ou generalizar resultados; os esforços se dirigem para o reconhecimento das práticas que produzem os sujeitos e objetos.

\begin{abstract}
Práticas essas, mais ou menos metódicas, mais ou menos intencionais, [...] [entendidas como] processos e técnicas [dispositivos] usados em diferentes contextos institucionais, para operar sobre o comportamento dos indivíduos, tomados individualmente ou em grupo - para modelar, dirigir, para modificar a maneira deles se conduzirem a si próprios [...]. [Podemos dizer que são os] modos simultâneos de agir e pensar (LOBO, 1997, p. 05).
\end{abstract}

Este dispositivo $^{7}$ permite identificar a forma como os sujeitos governam a si mesmos e se deixam governar uns pelos outros. O pesquisador deve ir em busca das práticas singulares, aquelas que surpreendem; os abalos e os acasos que mexem com as estruturas trazendo à tona contradições,

\footnotetext{
${ }^{7} \mathrm{O}$ dispositivo é uma situação criada no ambiente da pesquisa com o objetivo de provocar determinados comportamentos, falas, atitudes que no ambiente cotidiano não vêm a tona. Podemos também definir como acontecimentos que fogem a uma determinada normalidade ou expectativa e que permitem vislumbrar ações capazes de revelar as relações institucionais presentes num determinado espaço. Para Lourau (1993) é um conjunto de práticas planejadas e executadas com vista a provocar uma intervenção num determinado espaço. Coimbra define dispositivos como "um elemento que introduz diversos tipos de contradições na lógica da organização instituída, enunciando suas determinações, revelando a estrutura institucional”. (1995a, p. 64)
} 
muitas vezes, não percebidas. Precisa garantir espaço para circular dizeres e saberes coletivos que permitem a compreensão dos modos de produção de conhecimentos, de linguagens e apropriação dos espaços próprios dos participantes da pesquisa (GALVÃO, 2004).

As regras, muitas vezes, engessam as relações impedindo que os sujeitos tenham autonomia na busca de soluções para os problemas cotidianos. O primeiro desafio, portanto, que a pesquisa-intervenção propõe, é inserir no espaço da pesquisa, ações/dispositivos que abalem a ordem estabelecida, que mexam com as certezas e permitam investigar a produção de conceitos, significados, comportamentos, histórias e corporalidades, no âmbito das práticas corporais ${ }^{8}$. Um segundo desafio seria redimensionar a visão tradicional que, muitas vezes, se tem acerca da pesquisa, que privilegia a busca de dados objetivos, a mensuração, a generalização dos resultados, para dar volume às vozes que ecoam pelos diferentes espaços institucionais, voltar-se para os corpos que se mostram diferentes do esperado, ouvir os lamentos, as revoltas, as alegrias, os desejos, possibilitar o grito, o movimento, estar atento ao caráter "único e agudo" dos acontecimentos. Foucault, na investigação genealógica afirma que:

As forças que se encontram em jogo na história não obedecem nem a uma destinação, nem a uma mecânica, mas ao acaso da luta. Elas não se manifestam como formas sucessivas de uma intenção primordial; como também não têm o aspecto de um resultado. Elas aparecem sempre na álea singular do acontecimento (FOUCAULT, 1979, p. 28).

A opção por este caminho metodológico coloca o pesquisador de frente com determinadas regras. Para compreender a produção de corporalidades no interior das instituições é necessário considerar o ponto de vista daqueles que compõem esta instituição, suas vicissitudes, sua cultura e suas práticas, seus medos e tabus, suas crenças e perspectivas, é preciso, portanto, um contato direto com esses sujeitos, aprendendo com eles, mas também percebendo suas contradições.

Na pesquisa intervenção, o pesquisador é ao mesmo tempo indutor e receptor de práticas, ele interfere e sofre interferências da realidade. Nesse processo de interferência, existe uma confluência de saberes e produção coletiva de novos conhecimentos. Isto demonstra a necessidade de pensar formas de restituição do que é construído durante a pesquisa, formas de socializar os achados, pois o pesquisador não pode apenas restringir-se à coleta de informações sobre a realidade. A atitude que deve adotar é a de incentivo a reflexões, construir outras práticas, provocar o debate entre diferentes posições, possibilitar o encontro entre os sujeitos, com o pretexto de descobrir/contar

\footnotetext{
${ }^{8}$ Considero práticas corporais segundo a concepção de Foucault (1979), as ações dos corpos que incidem sobre o meio e sobre outros corpos, seja direta ou indiretamente.
} 
a história de suas vivências. Neste sentido, Lourau (1993, p. 56) afirma que:

\begin{abstract}
A pesquisa, para nós, continua após a redação final do texto, podendo até mesmo, ser interminável. Se a população estudada recebe esta restituição, pode se apropriar de uma parte do status do pesquisador, se tornar uma espécie de 'pesquisador coletivo', sem a necessidade de diplomas ou anos de estudos superiores, e produzir novas restituições, tanto ao agora talvez ex-pesquisador, quanto ao presente social mais imediato e global. Isso seria, efetivamente, a socialização da pesquisa.
\end{abstract}

A pesquisa deve constituiu-se numa oportunidade de (re)examinar os encontros/desencontros/reencontros da formação do pesquisador e aprofundar a percepção das formas de produção de conhecimento a partir das relações de poder-corpo-subjetividade dos sujeitos institucionais, procurando compreender um pouco mais seus mecanismos e implicações. À medida que o pesquisador se envolve com a realidade, consegue rever/reestruturar os desejos e intenções diante das relações vivenciadas. A pesquisa pode ser um caminho para fluir o debate relativo às funções das diferentes instituições sociais no mundo atual. Pode representar uma possibilidade de reflexão sobre os sujeitos e suas relações/interações, assim como a produção de subjetividade nestes/por estes espaços. Afinal, num mundo em que os espaços parecem sucumbir diante da importância do tempo, há que se considerar o lugar destinado aos diferentes sujeitos que independente do tempo continuam sendo institucionalizados. Que sujeitos têm sido criados e/ou permitidos existir neste mundo "sem fronteira"? Onde se quer chegar e onde efetivamente estamos chegando?

\title{
Referências
}

AGUIAR, K; ROCHA, M. Pesquisa-Intervenção e a produção de novas análises. Psicologia Ciência e Profissão, n. 23, 7, p. 64-73, 2003.

ASSMANN, Hugo. Paradigmas Educacionais e corporeidade - $3^{\text {a }}$ Edição. Piracicaba, São Paulo: UNIMEP, 1995, p. 82.

AZEVEDO, I. B. de. O prazer da produção científica: diretrizes para a elaboração de trabalhos acadêmicos. $5^{\text {a }}$ ed. Piracicaba, São Paulo: UNIMEP, 1997.

CARDOSO JR, H. R. Foucault inventa uma nova relação com a história. In: XIX Semana de História da Unesp: O olhar historiográfico dos anos 90, 2001, Assis - SP. XIX Semana de História da Unesp, 2001. v. 1. p. 120-120.

COIMBRA, Cecília Maria Bouças e NASCIMENTO, Maria Lívia do. Sobre implicação: práticas de esvaziamento político? [2003-]. Disponível em http://www.slab.uff.br/images/Aqruivos/textos_sti/Maria\%20L\%C3\%ADvia\%20do\%20Nascimen to/texto22.pdf. Acesso em: 15 fev. 2017.

LIMA, Dalva Aparecida e RIANI, Érika. Análise Institucional. 2004. Disponível em: http://www.academia.edu/9285718/N\%C3\%81LISE_E_INTERVEN\%C3\%87\%C3\%83O_INSTI 
TUCIONAL. Acesso em 05 mar. 2017.

FOUCAULT, M. Microfísica do poder. Rio de Janeiro: Graal, 1979.

GUATTARI, Félix. e ROLNIK, Suely. Micropolítica: Cartografias do Desejo. $6^{\mathrm{a}}$ ed. Petrópolis, Rio de Janeiro: Vozes, 2000.

GALVÃO, Edna Ferreira Coelho. A produção de corporalidades na escola: uma análise do projeto de Educação de Jovens e Adultos em Angra dos Reis. 2004. 242f. Tese (Doutorado em Educação) - Programa de Pós Graduação em Educação. Universidade Federal Fluminense, Niterói/RJ,2004.

GALVÃO, Juarez B. Saberes, significados e sentidos escolares sobre a exploração da bauxita na Amazônia. 2014. Tese (Doutorado em Currículo) _ Programa de Pós- Graduação em Educação. Pontifícia Universidade Católica de São Paulo, São Paulo, 2014.

LEMOS, Flavia Cristina Silveira e CARDOSO JÚNIOR, Hélio Rebello. A genealogia em Foucault: uma trajetória. Psicologia \& Sociedade; 21 (3): 353-357, 2009. Disponível em: http://www.scielo.br/pdf/psoc/v21n3/a08v21n3.pdf. Acesso em: 05 mar. 2017.

LOBO, Lilia. Ferreira. Os Infames da História: a instituição das deficiências no Brasil. 1997. 2 Vol. 407 f. Tese (Doutorado em Psicologia) Programa de Pós-Graduação em Psicologia da Pontifícia Universidade Católica do Rio de Janeiro 1997.

LOURAU, R. Sociólogo em Tempo Inteiro. Lisboa, Editorial Estampa, 1979. Análise Institucional e práticas de pesquisa. Rio de Janeiro. UERJ, 1993.

MARTON, Scarlett. Extravagâncias: ensaios sobre a filosofia de Nietzsche. São Paulo: UNIJUÍ, 2000.

PASSOS, E. e BENEVIDES, R. A construção do plano da clínica e o conceito de transdisciplinaridade. Psic Teor. e Pesq. Brasília, v. 16, n. 1, p. 71-79, jan./abr. 2000.

PAULON, Simone Mainieri. A análise de implicação como ferramenta na pesquisa-intervenção. Disponível em: http://www.scielo.br/pdf/psoc/v17n3/a03v17n3. Acesso em: 15 fev. 2017.

ROSSI, André; PASSOS, Eduardo. Análise institucional: revisão conceitual e nuances da pesquisa-intervenção no Brasil. Rev. Epos. vol.5 no.1 Rio de Janeiro jun. 2014. Disponível em: http://pepsic.bvsalud.org/scielo.php?script=sci_arttext\&pid=S2178700X2014000100009. Acesso em 20 mar. 2017.

RODRIGUES, H.C. (2002). A beira da brecha: uma história da análise institucional francesa nos anos 60. Disponível em < http://www.acheronta.org>. Acessado em 20 mar. 2002.

RODRIGUES, Heliane de .B.C. e SOUZA, V.L.B. A Análise Institucional e a Profissionalização do Psicólogo. In. KAMKHAGI, V.R. e SAIDON, O. (Orgs.). Análise Institucional no Brasil. Rio de Janeiro: Espaço e Tempo, 1987.

RODRIGUES, H. B. C. As subjetividades em revolta: institucionalismo francês e novas análises. 1994. Dissertação (Mestrado) - Programa de Pós-Graduação do Instituto de Medicina Social/UERJ, Rio de Janeiro, 1994. 